\title{
Evolution of parasitism and mutualism between filamentous phage M13 and Escherichia coli
}

Jason W Shapiro, Elizabeth SCP Williams, Paul E Turner

Background: How host-symbiont interactions coevolve between mutualism and parasitism depends on the ecology of the system and on the genetic and physiological constraints of the organisms involved. Theory often predicts that greater reliance on horizontal transmission favors increased costs of infection and may result in more virulent parasites or less beneficial mutualists. We set out to understand transitions between parasitism and mutualism by evolving the filamentous bacteriophage M13 and its host Escherichia coli.

Results: The effect of phage M13 on bacterial fitness depends on the growth environment, and initial assays revealed that infected bacteria reproduce faster and to higher density than uninfected bacteria in 96-well microplates. These data suggested that M13 is, in fact, a facultative mutualist of $E$. coli. We then allowed E. coli and M13 to evolve in replicated environments, which varied in the relative opportunity for horizontal and vertical transmission of phage in order to assess the evolutionary stability of this mutualism. After 20 experimental passages, infected bacteria from treatments with both vertical and horizontal transmission of phage had evolved the fastest growth rates. At the same time, phage from these treatments no longer benefitted the ancestral bacteria.

Conclusions: These data suggest a positive correlation between the positive effects of M13 on E. coli hosts from the same culture and the negative effects of the same phage toward the ancestral bacterial genotype. The results also expose flaws in applying concepts from the virulence-transmission tradeoff hypothesis to mutualism evolution. We discuss the data in the context of more recent theory on how horizontal transmission affects mutualisms and explore how these effects influence phages encoding virulence factors in pathogenic bacteria. 
1 Evolution of parasitism and mutualism between filamentous phage M13 and Escherichia

2 coli

3 Jason W. Shapiro ${ }^{1,2,3}$, Elizabeth SCP Williams ${ }^{1,5}$, and Paul E. Turner ${ }^{1,4}$

$4 \quad{ }^{1}$ Department of Ecology and Evolutionary Biology, Yale University

5 2Current address: Department of Biology, Loyola University Chicago, 1032 W. Sheridan Rd.,

6 Chicago, IL 60660, ${ }^{3}$ Corresponding author email: jshapiro2@luc.edu

$7 \quad{ }^{4}$ email: paul.turner@yale.edu

8 5email: elizabeth.williams@yale.edu

9

10 Keywords: experimental evolution, symbiosis, transmission mode, tolerance, pleiotropy

11 


\section{Abstract}

13 Background: How host-symbiont interactions coevolve between mutualism and parasitism

14 depends on the ecology of the system and on the genetic and physiological constraints of the

15 organisms involved. Theory often predicts that greater reliance on horizontal transmission favors

16 increased costs of infection and may result in more virulent parasites or less beneficial

17 mutualists. We set out to understand transitions between parasitism and mutualism by evolving

18 the filamentous bacteriophage M13 and its host Escherichia coli.

19 Results: The effect of phage M13 on bacterial fitness depends on the growth environment, and

20 initial assays revealed that infected bacteria reproduce faster and to higher density than

21 uninfected bacteria in 96-well microplates. These data suggested that M13 is, in fact, a

22 facultative mutualist of E. coli. We then allowed E. coli and M13 to evolve in replicated

23 environments, which varied in the relative opportunity for horizontal and vertical transmission of

24 phage in order to assess the evolutionary stability of this mutualism. After 20 experimental

25 passages, infected bacteria from treatments with both vertical and horizontal transmission of

26 phage had evolved the fastest growth rates. At the same time, phage from these treatments no

27 longer benefitted the ancestral bacteria.

28 Conclusions: These data suggest a positive correlation between the positive effects of M13 on $E$.

29 coli hosts from the same culture and the negative effects of the same phage toward the ancestral

30 bacterial genotype. The results also expose flaws in applying concepts from the virulence-

31 transmission tradeoff hypothesis to mutualism evolution. We discuss the data in the context of

32 more recent theory on how horizontal transmission affects mutualisms and explore how these

33 effects influence phages encoding virulence factors in pathogenic bacteria. 


\section{Introduction}

35 A microbial symbiont is a microorganism that depends on a host for completion of at least a 36 portion of its life cycle. Given this broad definition, symbionts may be helpful (mutualistic) or

37 harmful (parasitic) to their hosts. Further, evidence from natural symbiont populations indicates

38 that beneficial symbionts can evolve from harmful progenitors, and vice versa (Weeks et al.

39 2007; Sachs, Ehinger \& Simms 2010; Sachs, Skophammer \& Regus 2011). To fully comprehend

40 how symbiotic interactions evolve, it is necessary to consider the evolution of both parasites and

41 mutualists.

42 Though discussion of mutualists and parasites often occurs separately in the scientific

43 literature, all host-symbiont interactions may produce some benefits and some costs to host

44 fitness (Bronstein 2001). Thus, a mutualist is a symbiont whose benefits to the host exceed any

45 costs, whereas a parasite has the opposite cost-benefit relationship. As such, any change to the

46 selective environment that shifts selection on the benefits and costs of the interaction may also

47 drive an evolutionary transition from parasitism to mutualism or from mutualism to parasitism.

48 In both the parasitism and mutualism literatures, the relative opportunity for horizontal

49 versus vertical transmission is thought to play an important role in the evolution of symbiont

50 effects on host fitness (May \& Anderson 1983; Ewald 1987; Bull, Molineux \& Rice 1991; Bull

51 1994; Ebert 1994; Day 2001; Wilkinson \& Sherratt 2001; Ferdy \& Godelle 2005; Foster \&

52 Wenseleers 2006; Shapiro \& Turner 2014). Horizontal transmission occurs when a symbiont

53 enters a new host either through direct contact with an unrelated, infected host, or through

54 contact with a free symbiont in the host's environment. Both parasites and mutualists can be

55 horizontally transmitted. In contrast, vertical transmission is the direct intergenerational transfer

56 of a symbiont from an infected parent to its offspring during reproduction. The virulence- 
57 transmission tradeoff hypothesis postulates that when symbiont fitness depends more on

58 horizontal than on vertical transmission, negative effects on current host fitness will have

59 minimal impact on symbiont fitness, and the average cost of infection to the host (virulence) may

60 increase (Ewald 1987; Bull 1994; Read 1994). Alternatively, if symbiont fitness depends more

61 on vertical transmission to host offspring, then symbiont fitness and host fitness are directly

62 linked, and this covariance should select for reduced costs of the symbiont to its host, and

63 potentially for greater benefits, if possible (Axelrod \& Hamilton 1981; Doebeli \& Knowlton

64 1998; Herre et al. 1999; Foster \& Wenseleers 2006). More recent theory suggests that horizontal

65 transmission can also accelerate the evolution of mutualistic symbioses if there exists a

66 mechanism that creates a positive correlation between horizontal transmission and the benefits

67 that symbionts provide to their hosts (Shapiro \& Turner 2014). This theory suggests that while

68 one might still expect horizontal transmission to favor the evolution of greater virulence in

69 parasites, its effects on the evolution of mutualism are more difficult to predict and will depend

70 on the mechanisms underlying the interaction.

72 Experimental system

73 Although viruses are often assumed to be strictly parasitic, increasing evidence shows that some

74 viruses benefit their hosts. Examples of mutualistic viruses include Curvalaria thermal tolerance

75 virus, which enables Yellowstone panic grass to survive in soils at high temperatures (Marquez et al. 2007), the polydnaviruses of parasitoid wasps that suppress the immune systems of other

77 insects to allow the survival of wasp eggs (Summers \& Dibhajj 1999), and bacteriophage CTXФ,

78 which enables Vibrio cholerae bacteria to infect the guts of humans and other animals (Waldor

79 \& Mekalanos 1996). СТXФ is a filamentous phage in the single-stranded DNA virus family 
80 Inoviridae, which contains other viruses that may enhance bacterial pathogenicity (e.g. Pf4 in

81 Pseudomonas aeruginosa (Rice et al. 2009) and CUSФ in both Escherichia coli O18:K1:H7 and

82 Yersinia pestis (Gonzalez et al. 2002)). Temperate bacteriophages, which go through cycles of

83 dormancy and lytic activity, may also be facultative mutualists, as these viruses can carry genes,

84 such as for antibiotic resistance (e.g. Fard, Barton \& Heuzenroeder 2011) or virulence factors

85 (Herold, Karch \& Schmidt 2004), that benefit their hosts in certain environments. Here, we use the filamentous phage M13 (family Inoviridae) and its host, E. coli, as an

87 empirical model for studying evolutionary transitions between parasitism and mutualism in

88 response to altered dependence on vertical and horizontal modes of transmission. Filamentous

89 phages provide a powerful model for studying the evolution of symbiosis, because these viruses

90 infect a bacterial cell and produce thousands of progeny viruses without killing the host (Marvin

$91 \&$ Hohn 1969). Further, daughter cells inherit the infection from their parent, such that M13

92 experiences vertical transmission. Over several generations, uninfected daughter cells also arise

93 through the stochastic loss of phage replicative form DNA. Though infected cells are resistant to

94 superinfection (infection by another M13 virion), these uninfected bacterial cells can generally

95 be reinfected (Merriam 1977; Lerner \& Model 1981). Thus, M13 naturally undergoes both

96 vertical and horizontal transmission.

97 Prior work has shown that filamentous phages carrying antibiotic resistance genes could 98 evolve through serial transfer to enhance the benefits they provide bacteria (Bull, Molineux \&

99 Rice 1991; Bull \& Molineux 1992). In the present study, we set out to test if benefits of phage

100 infection could arise de novo. Many proteins encoded by M13 and related phages have

101 pleiotropic effects on host phenotypes, with particularly dramatic impacts on the permeability of

102 the bacterial outer membrane (Boeke, Model \& Zinder 1982; Marciano, Russel \& Simon 2001). 
103 Though we do not directly test for the effects of any particular protein, we suspected that these

104 pleiotropic effects may create avenues for mutualism evolution.

105

106 Experimental overview

107 To test how transmission mode affects the evolution of symbiont effects on host fitness, we

108 experimentally passaged M13 and E. coli in four replicated environments that differed in the

109 availability of naïve, susceptible hosts (i.e., opportunity for horizontal transmission) at the start

110 of each experimental passage (Figure 1 diagrams the differences among treatments). We will

111 refer to these treatments as "No Host Addition" (N), "Low Host Addition" (L), "Medium Host

112 Addition" (M), and "Complete Host Addition" (C). We also included an "Uninfected" (U) E.

113 coli control. The first four treatments represent a gradient from rare horizontal transmission

114 events to regular horizontal transmission at each passage. Further, coevolution may also have

115 taken place in treatments where both M13 and E. coli could evolve (N, L, and M). While our

116 data will address this possibility, and we will discuss it in more detail in the Discussion, we will

117 refrain from invoking the terms "coevolve" and "coevolution" through most of the text. Instead,

118 we will describe M13 and E. coli that evolved in the same experimental replicate as having been

119 "co-resident," as this term accurately captures their shared evolutionary history without assuming

120 that evolution by either species is the result of reciprocal evolution by the other.

121 The cultures were grown in 96-well microplates in a plate reader in order to create a large

122 number of replicate populations per treatment. Unexpectedly, we found that ancestral M13

123 increased both bacterial growth rate and bacterial density, indicating that the phage is, in fact, a

124 mutualist of E. coli in the plate reader environment. After 20 serial passages, we assayed the

125 growth rates and maximum densities of evolved bacteria infected with their co-resident phage. 
126 We also assayed these growth traits for the original E. coli ancestor when infected with the same,

127 evolved phages. Contrary to common expectations, high rates of horizontal transmission did not

128 lead to a reduction or loss of the mutualism between co-resident phage and bacteria. In fact,

129 infected bacteria from treatments allowing both phage transmission modes had greater

130 improvement in growth rate than bacteria that evolved in the absence of phage. At the same time,

131 phage from these treatments evolved traits that reduced the fitness of the ancestral E. coli strain.

132 We discuss these results in light of recent theory on the evolution of mutualism and explore the

133 relevance of our findings for phage contributions to the evolution of virulence in pathogenic

134 bacteria.

135

136 Materials \& Methods

137 Strains of bacteria and phage

138 E. coli $\mathrm{CSH} 22\left(\lambda^{-}\right.$, thi-, trpR ${ }^{-}, \Delta($ lac-pro $\left.)\right)$ is an $\mathrm{F}^{\prime} \mathrm{K} 12$-derived strain from the Cold Spring

139 Harbor Laboratory collection, notable for a lac-pro deletion on the host chromosome that is

140 complemented by a lac-pro insertion on the F' plasmid (F128). The F' plasmid is therefore

141 required for host growth in minimal medium lacking proline. CSH22 was obtained from the Coli

142 Genetic Stock Center at Yale University. Strain JS002 was created by transforming CSH22 with

143 the plasmid pJS001 (construction described below).

144 A high-titer stock of phage M13 was generously provided by K. Brooks Low at Yale

145 University. All experiments were initiated from a plaque-purified clone of M13 which was

146 sequenced and found to be identical to the published wild-type "Rutgers" strain [GenBank:

147 JX412914]. 


\section{Plasmid construction}

150 Expression of the channel protein, $\mathrm{g} 4 \mathrm{p}$, of filamentous phages is the strongest known inducer of

151 the phage shock operon in E. coli, of which $p s p A$ is a negative regulator (Model, Jovanovic \&

152 Dworkin 1997). We obtained the plasmid pDsRedExpress-2 (Clontech), which contains the red

153 fluorescent protein, DsRedExpress-2 downstream of a lac promoter. We amplified the $p s p A$

154 promoter region (Dworkin, Jovanovic \& Model 1997) from CSH22 using primers SpspAFW

155 (AACCAGCGGAAGAGCTAGCGAGTTCATCAAG) and HpspARV

156 (CTAAAAGCTTCCAGTTTCTGTGGATCTTCC), which also inserted SapI and HindIII

157 restriction sites at the 5' and ' ' ends of the pspA promoter (underlined). We then excised the $l a c$

158 promoter from pDsRedExpress-2 by digestion with SapI and HindIII (New England Biolabs) and

159 inserted the $p s p A$ promoter using T4 DNA ligase (New England Biolabs). The final plasmid is

160 designated pJS001 and hosts bearing this plasmid express red fluorescence when infected by

161 filamentous phages.

162

163 Growth medium

164 All cultures were grown in Davis Minimal (DM) medium supplemented to $0.1 \%$ with glucose

165 (often called DM1000). Cultures of JS002 were supplemented to100 $\mu \mathrm{g} / \mathrm{ml}$ with ampicillin when

166 grown overnight to ensure retention of pJS001.

167

168 Serial passage protocol and freezer storage

169 All experimental evolution was carried out in BD Falcon 96-well microplates with lids

170 (\#351172) in a Tecan F400 plate reader at $37^{\circ} \mathrm{C}$. The microplate was shaken orbitally for 30

171 seconds every 10 minutes (to maintain aeration and to help prevent cell clumping), followed by 2 
172 seconds of linear shaking (to improve uniform cell suspension) and measurement of absorbance

173 at $600 \mathrm{~nm}\left(\mathrm{OD}_{600}\right)$. Continuous shaking was avoided to reduce the probability of hardware

174 malfunction and well-to-well contamination.

175 The experiment was split into 5 experimental treatments: No Host Addition (N), Low

176 Host Addition (L), Medium Host Addition (M), Complete Host Addition (C), and Uninfected

177 (U) (see Figure 1 for a schematic of the setup). All treatments were replicated in 18 wells and

178 serially transferred for a total of 20 passages. In treatments N, L, M, and C, all wells were

179 initiated by inoculating $2 \mu \mathrm{l}$ of an M13-infected E. coli CSH22 overnight culture in $198 \mu \mathrm{l}$ of

180 DM1000, whereas treatment $\mathrm{U}$ wells were similarly initiated with $2 \mu \mathrm{l}$ of uninfected $E$. coli

$181 \mathrm{CSH} 22$. After 24 hours of culture under the conditions described above, $2 \mu$ of each population

182 in treatments $\mathrm{N}$ and $\mathrm{U}$ were added to $198 \mu \mathrm{l}$ of fresh medium in a fresh microplate. To

183 manipulate treatment $\mathrm{L}, 2 \mu \mathrm{l}$ of each population were added to $196 \mu \mathrm{l}$ of DM1000 with $2 \mu \mathrm{l}$ of a

184 1:100 diluted overnight culture of ancestral E. coli CSH22, such that $\sim 1 \%$ of the bacteria were

185 uninfected and susceptible at the start of the passage. Treatment $\mathrm{M}$ was manipulated so that $1 \mu \mathrm{l}$

186 of the population was added to $198 \mu \mathrm{l}$ of DM1000 with $1 \mu \mathrm{l}$ of undiluted overnight $E$. coli

$187 \mathrm{CSH} 22$, resulting in $\sim 50 \%$ of the starting bacteria as uninfected and susceptible.

188 After passaging wells for treatments N, L, M, and U, the microplate was centrifuged for

18915 minutes at $4000 \mathrm{rpm}$, and the top $100 \mu \mathrm{l}$ of each treatment $\mathrm{C}$ well were transferred to a fresh

190 96-well microplate for freezer storage and dilution. Each treatment $\mathrm{C}$ population was diluted $10^{6}-$

191 fold, because preliminary assays indicated that this dilution would maintain a population size of

$192 \sim 10^{4}$ particle-forming units (pfu) per $2 \mu 1$ at time of transfer. Centrifugation and dilution steps

193 also eliminated infected hosts prior to serial passage; $2 \mu 1$ of each $10^{6}$-fold dilution of virus was 
194 then added to $196 \mu \mathrm{l}$ of DM1000 with $2 \mu \mathrm{l}$ of overnight $E$. coli $\mathrm{CSH} 22$ so that $100 \%$ of the

195 starting bacteria was uninfected and susceptible.

196 Prior to each experimental passage, the top $100 \mu \mathrm{l}$ of each well for treatments N, L, M,

197 and C were transferred to a sterile, polypropylene 96-well microplate (USA Scientific 1830-

1989600 ) and mixed with $100 \mu \mathrm{l}$ of $80 \%$ glycerol for storage at $-80{ }^{\circ} \mathrm{C}$. Undiluted phage from

199 treatment $\mathrm{C}$ were also topped with $100 \mu \mathrm{l}$ of $80 \%$ glycerol and stored at $-20{ }^{\circ} \mathrm{C}$ in the dilution 200 plate.

201

202 Infecting ancestor $\mathrm{E}$. coli with evolved phage

203 Approximately $1 \mu \mathrm{l}$ of frozen culture was taken from the Day 20 stock plate for each assayed

204 population by "stabbing" with a pipette tip, and then inoculated directly into $200 \mu 1$ of fresh

205 medium. The plate was incubated for 24 hours as described above, and each well was then

206 filtered (Costar Spin-X centrifuge tubes \#9301) to remove bacteria. $2 \mu$ of each phage stock and

$2072 \mu \mathrm{l}$ of an overnight culture of CSH22 were then added to $196 \mu$ of DM1000 and incubated in

208 the microplate reader. After 24 hours, each well was serially diluted $10^{-5}$ and $50 \mu$ of each

209 dilution were spread on DM1000 agar. Plates were incubated for 48 hours at $37^{\circ} \mathrm{C}$ to obtain

210 colonies of ancestral CSH22 bacteria infected with evolved phage.

211

212 Growth rate assays

213 We assayed growth rates of bacteria infected with their co-resident phage, and of the original $E$.

214 coli ancestor infected by these same, evolved phages. Assays of evolved phage in the co-resident

215 and original ancestral host backgrounds were completed within the same 96-well microplate and

216 same experimental block. Populations were randomly distributed across the days (blocks) of the 
217 assays, with treatments equally represented across blocks. For controls, in each assay plate we

218 included uninfected ancestor E. coli $\mathrm{CSH} 22$ and the same bacteria infected with the ancestral

219 M13.

220 To obtain growth curves of evolved bacteria infected by their co-resident phage, $1 \mu \mathrm{l}$ of

221 the corresponding frozen stock was inoculated as described above in triplicate, using a

222 randomized design across a 96 well plate. Virus infections were confirmed in a preliminary spot

223 test assay in which each population was grown, filtered to remove bacteria, and then $2 \mu \mathrm{l}$ of

224 filtrate were plated on top of an LB agar (0.7\%) overlay with $200 \mu \mathrm{l}$ of ancestral CSH22 bacteria.

225 This assay was also performed to check for potential contamination of populations from

226 treatment $\mathrm{U}$. One population from that treatment tested positive for virus infection and this

227 population was excluded from later assays. Further, 15 of the 18 treatment $\mathrm{N}$ populations did not 228 yield phage. As a result, only the 3 remaining populations could be assayed for the effects of 229 phage on the ancestral E. coli (see below).

230 To obtain growth curves of ancestral bacteria newly-infected with evolved phage, two

231 randomly-chosen infected colonies were individually picked using a pipette tip and added to

232 separate wells. The plate was vortexed briefly, and $2 \mu \mathrm{l}$ of the wells containing bacteria from

233 infected colonies were added to new wells containing $196 \mu$ l of DM1000 and $2 \mu 1$ of the red-

234 fluorescent assay host, JS002 in order to confirm infection. This indicator host was only used to

235 confirm infections in the newly infected colonies. Growth data are reported from the

236 corresponding wells without the indicator host. The plate was then vortexed briefly and

237 incubated in the plate reader at $37^{\circ} \mathrm{C}$ for 24 hours, taking measurements of $\mathrm{OD}_{600}$ and red

238 fluorescence (Ex: 544, Em: 590) every 10 minutes. The red fluorescence assay confirmed that

239 colonies were infected in the vast majority of cases. Data from uninfected colonies were 
240 excluded from the statistical analyses. In rare cases, infected bacteria did not grow sufficiently

241 within the 24 hour timespan of the assay, and these data were excluded as well, as it would not

242 be possible to distinguish between an extended lag phase and slow exponential growth in these

243 instances. As mentioned above, free phage could only be recovered from 3 out of 18 treatment $\mathrm{N}$

244 populations. Of these three phage isolates, data from one population were excluded, because

245 infected bacteria did not grow measurably within the 24 hours allowed in the assay.

246 Because assays of co-resident phage and bacteria were initialized from frozen cultures,

247 whereas assays of ancestral bacteria infected by evolved phage were started from infected

248 colonies, minor differences in growth are expected due to potential differences in prior

249 acclimation to the plate reader environment. The ancestral controls included bacteria started from

250 both conditions and are presented separately in Figures 3 and 4. This difference in starting

251 condition appears to reduce the difference in final density between the infected and uninfected

252 ancestral controls but did not otherwise appear to affect assay results.

253

254 Data Analysis

255 Exponential growth rates of bacteria were determined for each growth curve in R (R Core Team

256 2015). The data were first smoothed in a moving window of 3 time points ( $\sim 30$ minutes) and the

257 exponential growth rate was then determined for every three consecutive points for all OD values

258 above the baseline of detection by the plate reader and below midlog. Maximum OD was also

259 recorded as the highest value obtained over the course of the 24 hour growth period for each

260 curve. This value was chosen as a proxy for yield, since stationary densities could not be

261 estimated for all curves due to noise in some curves late in growth, as well as slow-growing

262 cultures failing to reach a stationary density after 24 hours. 
264 1960; Sokal \& Rohlf 2012), implemented using the function leveneTest() in the 'car' package in

265 R (Fox \& Weisberg 2011). While heteroscedasticity was not observed in the data from growth of

266 the evolved bacteria with their co-resident phage, significant heteroscedasticity was observed in

267 growth data of ancestral bacteria infected with these same evolved phages (see Table S2 in the

268 Supplementary Material for statistics). These data were also notably non-normal in probability

269 plots (not shown). We used the Box-Cox transformation (Box \& Cox 1964; Sokal \& Rohlf 2012)

270 (estimated by boxcox() in the package 'MASS' in R (Venables \& Ripley 2002)) on the pooled

271 growth rate data, as well as on the pooled maximum density data from this second assay. The

272 estimated shape parameters were $\lambda=-0.66667$ and 0.141414 for the growth rate and maximum

273 density data, respectively. After transforming the data, both growth metrics were notably more

274 normal and homoscedastic. Higher variance among treatment $\mathrm{C}$ replicates and lower variance

275 among uninfected ancestral E. coli samples appeared to account for the original

276 heteroscedasticity. Test significance was corrected for multiple comparisons using the

277 Bonferroni method (Sokal \& Rohlf 2012). Two outliers with exceptionally fast growth (one

278 replicate of the infected ancestor in both assays) were excluded from statistical analyses.

280 Results

281 We carried out five experimental treatments with 18 replicate populations per treatment, serially

282 cultured in 96-well microtiter plates. Three treatments ("No Host Addition" (N), "Low Host

283 Addition" (L), and "Medium Host Addition" (M)) permitted both M13 and E. coli to evolve,

284 with addition of either $0 \%, 1 \%$, or $50 \%$ of naïve uninfected ancestral E. coli at the start of each

285 passage. In the "Complete Host Addition" (C) treatment, the phage populations were isolated 
286 and passaged each day with addition of $100 \%$ uninfected ancestral E. coli, preventing the

287 possibility for bacterial evolution. "Uninfected" (U) controls consisted of bacteria passaged in

288 the absence of phage.

289

290

Assay overview

291

After 20 passages, we carried out two assays to determine how the phage and bacteria

292 evolved across the treatments. In the first assay, we obtained growth curves of the evolved

293 bacteria when infected by their co-resident phage (treatments N, L, and M) as well as of the

294 uninfected, evolved bacteria (treatment U). This assay identifies broad changes in the

295 interactions between co-resident bacteria and phage, and the uninfected controls identify the

296 capacity for the bacteria to adapt to the experimental environment in the absence of phage

297 infection. In the second assay, we isolated phage from each treatment in which phage could

298 evolve (N, L, M, and C) and used these phage to infect the ancestral E. coli. We then obtained

299 growth curves of these newly infected, ancestral bacteria. This assay identifies the extent to

300 which phage evolution can explain changes in the growth of the infected, co-resident bacteria

301 from the first assay.

302 In each assay, we analyzed the maximum growth rate and the maximum $\mathrm{OD}_{600}$ as proxies

303 for the absolute fitness of the bacteria. These two fitness components were strongly, positively

304 correlated $\left(\mathrm{R}^{2}=0.77\right.$ with untransformed data, $\mathrm{p}<0.0001$; see Figure 2$)$. This positive

305 relationship is important for interpreting the data, as a tradeoff between rate and maximum

306 density would make it difficult to use either metric as a proxy for fitness. Interestingly, there

307 appears to be greater constraint on the evolution of yield than on rate across evolving

308 populations. We will explore this observation in more detail in the Discussion. 
310 Growth of evolved uninfected bacteria and of evolved bacteria infected with co-resident phage

311 We obtained triplicate growth curves for each of the evolved bacterial populations infected with

312 their co-resident phage (treatments N, L, and M; see Figure 3). We also assayed the uninfected

313 ancestor E. coli $(n=6)$, the ancestor infected with the ancestral M13 phage $(n=5)$, and the

314 bacteria evolved in the absence of phage (U controls). Results for ancestral strains confirmed that

315 the infected ancestral bacteria grew significantly faster and to significantly higher density than

316 the uninfected ancestor (2-sided $t$ tests, $\mathrm{p}<0.0001$ and $\mathrm{p}=0.007$, respectively), demonstrating

317 that the ancestral infection is mutualistic in the plate reader environment. Results for the U

318 controls showed that uninfected $E$. coli adapted to the plate reader environment, increasing in

319 both growth rate and cell density relative to the uninfected ancestor. While evolved uninfected

320 bacteria also grew to higher maximum densities than the infected ancestral bacteria (2-sided $t$

321 test, $\mathrm{p}<0.0001)$ they did not grow significantly faster than the infected ancestor (2-sided $t$ test, $\mathrm{p}$ $322=0.8392)$.

323 For both fitness components, there were significant differences among treatments N, L,

$324 \mathrm{M}$, and $\mathrm{U}$, and between these treatments and the infected ancestral bacteria (One-way ANOVAs

325 and t-tests summarized in Tables 1 and 2). On average, bacteria from all treatments evolved a

326 similar maximum density that exceeded that of the uninfected and infected ancestors (see Figure

327 3a). This similarity suggested that improvement in maximum density may have been driven by

328 the bacteria alone, and that phage infection did not significantly affect this increase.

329 We observed greater variation among treatments in the evolution of growth rate. There

330 was significant variation among treatments that started with phage $(\mathrm{N}, \mathrm{L}$, and $\mathrm{M})$ and the

331 infected ancestral bacteria (One-way ANOVA comparing N, L, M, IA, p = 0.0141). Further, this 
332 difference is largely driven by evolution in treatment $\mathrm{L}$, which was the only treatment that grew

333 significantly faster than the infected ancestor when tested in pairwise comparisons (2-sided $t$ test

334 of L vs infected ancestor, $\mathrm{p}=0.0058$ ). Additionally, Treatments $\mathrm{N}, \mathrm{L}$, and M grew significantly

335 faster, as a pooled group, than the uninfected evolved bacteria (2-sided t test, $\mathrm{p}=0.0015$ ). These

336 data suggest that phage infection affected the evolution of bacterial growth rate. Moreover, there

337 may be an intermediate level of naïve host availability near the $1 \%$ used in treatment $\mathrm{L}$ that

338 maximizes the evolution of bacterial growth rate.

339 Growth of ancestral bacteria infected with evolved phage

340 We next assayed the growth of ancestral E. coli, newly infected with evolved phage from each of

341 the four treatments containing M13 derivatives (i.e., treatments N, L, M, and C). This assay

342 informs the extent to which phage evolution alone is sufficient to explain the results from the

343 previous assay. Pairwise comparisons were not made between data from treatments N, L, and M,

344 as these were not significantly different in either measure by one-way ANOVA. Further, analysis

345 of treatment $\mathrm{N}$ phage was limited as free phage could only be recovered from 3 treatment $\mathrm{N}$

346 populations, as noted in the Methods. A possible explanation for the loss of phage production in

347 the 15 remaining treatment $\mathrm{N}$ populations is explored in the Discussion.

348 Surprisingly, bacteria infected with phage from treatment $\mathrm{C}$ did not grow significantly

349 differently from either the infected or uninfected, ancestral controls (see Tables 3 and 4). This

350 result contradicts the common expectation that horizontal transmission may select for increased

351 virulence. Instead, these data suggest that in the plate reader environment, horizontal

352 transmission does not select for virulent M13.

353 In contrast, while evolved, infected bacteria demonstrated enhanced growth in the first

354 assay, evolved phages from treatments $\mathrm{N}, \mathrm{L}$, and $\mathrm{M}$ significantly reduced both the growth rate 
355 and maximum density of the ancestral E. coli relative to infection by the ancestral phage (see

356 Tables 3 and 4 for statistics). Further, these phage reduced bacterial density below that of the

357 uninfected ancestor, effectively transforming a mutualism into a parasitic interaction (2-sided $t$

358 test of maximum OD of N, L and M together vs uninfected ancestor, $\mathrm{p}<0.0001$; see Figure 4).

359 This finding is particularly unexpected given the results of the first assay, in which phage had no

360 effect on the evolution of co-resident host density. These data suggest that the evolution of phage

361 virulence toward the ancestral host may be a byproduct of local adaptation of M13 to the co-

362 resident, evolving E. coli in treatments N, L, and M.

363

364 Discussion

365 Mixed transmission modes promote increased benefits to the host

366 Transmission mode plays multiple roles in the evolution of symbioses. While vertical

367 transmission is generally thought to create partner fidelity feedbacks between host and symbiont,

368 horizontal transmission provides opportunities for symbiont reproduction independent of the

369 original host (Foster \& Wenseleers 2006). Here, we tested the effects of differing opportunities

370 for horizontal and vertical transmission on the evolution of a facultatively mutualistic virus and

371 its host bacterium. The virulence-transmission tradeoff hypothesis would have predicted that

372 phage populations experiencing frequent horizontal transmission (treatments $\mathrm{C}$ and $\mathrm{M}$ ) would

373 evolve toward parasitism (reduced mutualism), whereas those with rare or no horizontal

374 transmission (treatments L and N) would maintain or evolve enhanced mutualism. Contrary to

375 this hypothesis, we did not observe the evolution of virulence in treatment $C$ phage. Instead, we

376 found that infected bacteria from treatments with both transmission modes improved in growth,

377 whereas their co-resident phage evolved traits that reduce the fitness of the ancestral host. 
378 Further, only infected bacteria from treatment L grew significantly faster than the infected

379 ancestor, implying a benefit of rare horizontal transmission to the evolution of mutualism.

380 These data appear to agree with more recent theory that proposed conditions under which

381 relatively rare horizontal transmission is expected to accelerate the evolution of benefits provided

382 by symbionts to hosts (Shapiro \& Turner 2014). In order to support this theory rigorously, we

383 would need to uncover a positive covariance between phage horizontal transmission and the

384 mechanism by which phage increase the fitness of infected bacteria. The likeliest mechanism

385 underlying this covariance would be pleiotropy, and it is possible for benefits, costs, and

386 horizontal transmission to all be tied up within the effects of a single gene. For instance, the

387 phage attachment protein, g3p, mediates cell entry, prevents superinfection by related phages,

388 and also increases membrane permeability (Boeke et al. 1982). Additional experiments and

389 molecular work would be required to test this hypothesis for the present study.

390 Alternative explanations for the observed differences in evolved phage effects on co-

391 resident and ancestral bacteria include the possibility that effective phage population size

392 differed among treatments or that phage adapted largely to the differences in the number of

393 ancestral bacteria present across treatments. Though possible, these explanations seem unlikely,

394 as phage in treatment L had the most significant phenotypic evolution, despite likely having

395 lower effective population size and host availability than in treatment $\mathrm{C}$, where no phage

396 evolution was observed.

398 The relationship between rate and maximum density across treatments

399 Figure 2 indicates a strong positive relationship between growth rate and maximum density for

400 the evolving and ancestral populations (both infected and uninfected) in this experiment. Further, 
401 the data demonstrate that over the relatively short duration of this study (20 passages), density

402 was constrained to a similar maximum across all treatments, whereas rate varied significantly,

403 with the greatest improvements in rate arising in the populations with phage. These results are

404 consistent with data from long term evolution studies in E. coli (Novak et al 2006), in which

405 yield remained mostly constant over thousands of generations while rate continued to improve.

406 The authors of that work, while testing for evolved tradeoffs between rate and yield also noted

407 that positive correlations between these fitness components would be expected during the earlier

408 stages of adaptation. It would be interesting to continue the current experiment for more

409 generations in order to test if phage infection significantly alters the emergence of a tradeoff

410 between rate and yield.

411

412 The potential role of coevolution

413 Coevolution is the reciprocal selection on two lineages over time (Janzen 1980). As noted in the

414 Introduction, coevolution in this sense was possible in treatments N, L, and M. While the assays

415 conducted do not directly test whether or not reciprocal selection took place, they do inform the

416 extent to which both partners evolved in each treatment and the role each played in the evolution

417 of bacterial growth rate and density.

418 Without evolution of both the bacteria and phage, it would not be possible for viruses

419 from treatments $\mathrm{N}, \mathrm{L}$, and $\mathrm{M}$ to harm the ancestral host while still helping the co-resident

420 bacteria. Further, phage evolution alone (treatment C) did not lead to significant changes in viral

421 phenotype, and bacterial evolution alone (treatment $\mathrm{U}$ ), while increasing growth rate and

422 maximum density, could not match the growth rate of infected, co-resident bacteria. These 
423 results suggest that coevolution may have played an important role in driving the observed 424 phenotypic changes.

425

426 Limitations in disentangling transmission mode and coevolution

427 Using the methods discussed, it is not possible to fully disentangle the effects of transmission

428 mode and coevolution. While additional assays and sequencing might uncover the mechanisms 429 underlying the observed results and the relative roles played by both partners, these methods, 430 too, cannot say precisely which of these selective forces had the greatest impact on the evolution 431 of M13 and E. coli. Further, it is not currently possible to cure the bacteria of M13 infection in 432 order to assay evolved bacteria in isolation of their co-resident phage. The likeliest method to 433 succeed would require treating infected bacteria with the antibiotic rifampicin, as rifampicin is 434 known to interfere with filamentous phage DNA replication (Brutlag, Schekman \& Kornberg 435 1971). Unfortunately, rifampicin is also known to cause loss of the F plasmid (Bazzicalupo \& 436 Tocchini-Valentini 1972), which the bacteria require for growth in the experimental

437 environment. Thus, chemically curing the bacteria of phage is unlikely to succeed without also 438 eliminating the F plasmid or selecting for bacterial resistance to the antibiotic. The latter would 439 then confound the assay by changing the bacterial genotype.

441 The loss of phage in vertically transmitted lineages

442 Given the observed benefits of the phage in the experimental environment, it may be surprising 443 that no phage are produced after evolution in 15 out of 18 replicates with predominantly vertical 444 transmission ( $\mathrm{N}$ treatment). While one might expect host resistance to evolve rapidly in response 445 to a parasite, why should hosts lose beneficial viruses under predominantly vertical transmission 
446 in our experiments? A similar result was observed in previous work in which M13 was modified

447 to carry an antibiotic resistance gene that benefitted its E. coli host (Bull, Molineux \& Rice 1991;

448 Bull \& Molineux 1992). The phage were evolved in treatments that manipulated vertical and

449 horizontal transmission, and phage production was lost under vertical transmission (Bull \&

450 Molineux 1992). In these cases, the authors observed deletions in the phage that resulted in their

451 maintenance as "cryptic plasmids" or that phage integrated into the bacterial chromosome (Bull

452 \& Molineux 1992).

453 In the present study, we also observed the maintenance of benefits associated with

454 infection in treatment $\mathrm{N}$ populations. One possible explanation is that our phage have also

455 evolved into a sort of "cryptic plasmid" as suggested in these earlier studies. We were unable to

456 recover plasmids using traditional miniprep methods, however, from the corresponding bacteria

457 (Sambrook, Fritsch \& Maniatis 1989). We also conducted PCR assays targeting phage genes and

458 performed full genome sequencing of six treatment $\mathrm{N}$ bacterial populations, and similarly did not

459 find evidence for virus integration into the bacterial genome. These data suggest the phage were

460 truly lost from these treatment $\mathrm{N}$ populations, though further sequencing efforts may be

461 necessary to be entirely certain.

462 An alternative hypothesis is that phage loss is a natural byproduct of viral life history

463 during vertical transmission. In the ancestral interaction, it is known that initial infection by M13

464 spurs the production of approximately 30-50 copies of the phage dsDNA within the cell, and this

465 copy number dwindles to around 5-15 per cell after vertical transmission (Lerner \& Model

466 1981). Without mechanisms to guarantee fair segregation of these copies into daughter cells,

467 phage-free cells should arise within a few generations (Merriam 1977; Lerner \& Model 1981).

468 Further, phage production per cell is expected to decline in established infections as a result of 
469 this lower RF copy number within infected bacteria. Even if beneficial to their hosts, eventual

470 loss of phage could be expected.

471 To test this "neutral loss hypothesis," we analyzed a discrete-time susceptible-infected

472 (SI) model of the experimental setup in R, including steps for dilution at serial passages. (Model

473 details are available in the Supplementary Material.) This model does not include any form of

474 mutation or evolution, but rather is intended as a test of under what parameter space one should

475 expect phage to go extinct in treatment N. We explored the model under a range of phage effects

476 on growth rate, from moderate parasitism to moderate mutualism, and also over a range of

477 intrinsic rates of retention. Ultimately, we find that even in the case of mutualists, phage loss can

478 be expected under rates of retention over $90 \%$ (Figure S1). While this model does not rule out

479 the possibility of phage parasitism and host resistance evolution, it demonstrates that vertical

480 transmission is not sufficient to maintain mutualists without sufficiently high rates of both

481 retention in infected hosts and transmission to new susceptibles. These observations also

482 correspond to model results from studies on conjugative plasmid maintenance over time

483 (Bergstrom, Lipsitch \& Levin, 2000).

484 Taken together, this model and previous observations of extinction under vertical

485 transmission (Merriam 1977; Bull \& Molineux 1992) suggest the phage's life history may have

486 spurred its own loss in treatment N. In light of the data, this explanation seems likely, as phage

487 are maintained in the $\mathrm{L}$ and $\mathrm{M}$ treatments, where there is a regular supply of susceptible hosts to

488 maintain the phage population and to allow for the eventual re-infection of co-resident bacteria. 
491 Two recent reviews highlighted that host evolution of tolerance can affect the long-term

492 evolution of parasite virulence and may enable transitions from parasitism to mutualism

493 (Edwards 2009; Oliver, Leather \& Cook 2009). Specifically, host evolution to tolerate the costs

494 of infection can enable the evolution of symbiont traits that increase both the benefits and costs

495 of infection to the host. In our work, this mechanism would explain how bacteria from treatments

$496 \mathrm{~L}$ and $\mathrm{M}$ improve in both rate and maximum density, despite the evolution of viral traits that are

497 harmful to the ancestral bacteria.

498 Though this study is focused on the evolution of a beneficial phage, this result has

499 important implications for virulence evolution in a variety of pathogens and in zoonoses, in

500 particular. Just as evolution of a virus on one host type can influence viral phenotypes in other

501 hosts (Turner et al. 2010), our data demonstrate how the evolution of tolerance by one host

502 genotype may select for symbiont traits that harm a naïve host. This observation also illustrates

503 why it can be so difficult to identify reservoir hosts for zoonotic diseases: it is not necessary for a

504 new zoonotic disease agent to have ever been virulent toward its reservoir host. A coevolutionary

505 history between a host and a symbiont of any type (parasite, commensal, or even mutualist) may

506 drive the evolution of an unexpectedly virulent disease in an alternate host genotype.

507 The data also provide insight into the evolution of filamentous prophages (e.g., Pf4,

508 СТХФ, and YРFФ) that contribute to the pathogenicity of their host bacteria (P. aeruginosa, $V$.

509 cholerae, and Y. pestis) toward humans (Waldor \& Mekalanos 1996; Gonzalez et al. 2002; Rice

510 et al. 2009). Though these phages appear to benefit their host bacteria within the context of the

511 bacteria's mammalian host, it is unclear how these phages affect bacterial fitness in other

512 environments or how these interactions have coevolved over evolutionary time. Our results show

513 that the filamentous phage M13, which has not been associated with E. coli pathogenicity, can 
514 evolve variation in its effects on E. coli, and this variation depends on both the ecology of phage

515 transmission and also on the experimental environment. During local epidemics, phage may

516 coevolve with their bacterial host in a manner that later decreases bacterial fitness outside of the

517 eukaryotic host. It is, therefore, important to consider how alternate environments shape the

518 evolution of related phages that contribute to bacterial pathogenicity.

\section{Conclusions}

521 In this study, we tested how transmission mode affects the evolution of parasitism and mutualism

522 in a bacteria-phage interaction. We observed the greatest increases in evolved host fitness when

523 both transmission modes were possible. Further, phage from these treatments evolved traits that

524 directly harmed the ancestral host, suggesting pleiotropy at the basis for both parasitism and

525 mutualism in this system. This result undermines the view that symbioses evolve along a

526 continuum between parasitism and mutualism, and instead suggests that discontinuous jumps

527 may occur rapidly as a result of changing environments or interacting with a naïve partner. This

528 inference may be particularly important when considering the emergence of zoonotic diseases or

529 the evolution of pathogenic bacteria in which phage carry virulence-associated genes.

530

531 Availability of supporting data

532 Raw growth curves, post-analysis growth rate and maximum density data, all statistical analyses

533 underlying Figures 2, 3, and 4 and Tables 1-4, and R code for the model of phage loss are

534 available through figshare (doi: 10.6084/m9.figshare.2066064). Raw sequencing reads from five

535 evolved Treatment N populations are available through NCBI's Sequence Read Archive

536 [SRP074196]. 


\section{Acknowledgments}

539 The authors are thankful to K. B. Low for providing wild-type M13 and to S. Alonzo, K. B.

540 Low, D. Vasseur, and G. P. Wagner for useful discussion. We are also grateful to J. Bull for

541 suggesting we explore a model of phage loss. We thank S. Wielgoss and two anonymous

542 reviewers for helpful comments on the paper. 


\section{References}

544 Axelrod, R., and W. D. Hamilton. The Evolution of Cooperation. Science. 1981; 211:1390-1396.

545 Bazzicalupo, P., and G.P. Tocchini-Valentini. Curing of an Excherichia coli episome by

546 rifampicin. Proceedings of the National Academy of Sciences of the United States of

$547 \quad$ America. 1972; 69 (2); 298-300.

548 Bergstrom, C.T., M. Lipsitch, and B.R. Levin. Natural selection, infectious transfer and the 549 existence conditions for bacterial plasmids. Genetics. 2000; 155 (4): 1505-1519.

550 Boeke, J. D., P. Model, and N. D. Zinder. Effects of bacteriophage f1 gene III protein on the host 551 cell membrane. Molecular \& General Genetics. 1982; 186:185-192.

552 Bronstein, J. L. The costs of mutualism. American Zoologist. 2001; 41:825-839.

553 Brutlag, D., R. Schekman, and A. Kornberg. A possible role for RNA polymerase in the 554 initiation of M13 DNA synthesis. Proceedings of the National Academy of Sciences of the $555 \quad$ United States of America. 1971; 68 (11): 2826-2829.

556 Bull, J. J. Perspective - Virulence. Evolution. 1994; 48:1423-1437.

557 Bull, J. J., and I. J. Molineux. Molecular-Genetics of Adaptation in an Experimental-Model of 558 Cooperation. Evolution. 1992; 46:882-895.

559 Bull, J. J., I. J. Molineux, and W. R. Rice. Selection of Benevolence in a Host-Parasite System. $560 \quad$ Evolution. 1991; 45:875-882.

561 Day, T. Parasite transmission modes and the evolution of virulence. Evolution. 2001; 55:23895622400.

563 Doebeli, M., and N. Knowlton. The evolution of interspecific mutualisms. Proceedings of the 564 National Academy of Sciences of the United States of America. 1998; 95:8676-8680. 
565 Dworkin, J., G. Jovanovic, and P. Model. Role of upstream activation sequences and integration

566 host factor in transcriptional activation by the constitutively active prokaryotic enhancer-

567 binding protein PspF. Journal of Molecular Biology. 1997; 273:377-388.

568 Ebert, D. Virulence and Local Adaptation of a Horizontally Transmitted Parasite. Science. 1994;

$569 \quad 265: 1084-1086$.

570 Edwards, D. P. The roles of tolerance in the evolution, maintenance and breakdown of

571 mutualism. Naturwissenschaften. 2009; 96:1137-1145.

572 Ewald, P. W. Transmission Modes and Evolution of the Parasitism-Mutualism Continuum.

573 Annals of the New York Academy of Sciences. 1987; 503:295-306.

574 Ferdy, J. B., and B. Godelle. Diversification of transmission modes and the evolution of

575 mutualism. American Naturalist. 2005; 166:613-627.

576 Foster, K. R., and T. Wenseleers. A general model for the evolution of mutualisms. Journal of

577 Evolutionary Biology. 2006; 19:1283-1293.

578 Fox, J. and S. Weisberg (2011). An $\{\mathrm{R}\}$ Companion to Applied Regression,

579 Second Edition. Thousand Oaks CA: Sage.

580 Gonzalez, M. D., C. A. Lichtensteiger, R. Caughlan, and E. R. Vimr. Conserved filamentous

581 prophage in Escherichia coli O18 : K1 : H7 and Yersinia pestis biovar orientalis. Journal of

$582 \quad$ Bacteriology. 2002; 184:6050-6055.

583 Herold, S., H. Karch, and H. Schmidt. Shiga toxin-encoding bacteriophages - genomes in

584 motion. International Journal of Medical Microbiology. 2004; 294 (2-3): 115-121.

585 Herre, E. A., N. Knowlton, U. G. Mueller, and S. A. Rehner. The evolution of mutualisms:

586 exploring the paths between conflict and cooperation. Trends in Ecology \& Evolution. 1999;

$587 \quad 14: 49-53$. 
588 Janzen, D.H. When is it coevolution? Evolution. 1980; 34 (3): 611-612.

589 Lerner, T.J. and P. Model. The "steady state" of coliphage fl: DNA synthesis late in infection.

$590 \quad$ Virology. 1981; 115: 282-294.

591 Levene, H. (1960). Robust tests for equality of variances. In Olkin, I., H. Hotelling, et al.

592 Contributions to probability and statistics: essays in honor of Harold Hotelling. Stanford

593 University Press. pp. 278-292.

594 Marciano, D. K., M. Russel, and S. M. Simon. Assembling filamentous phage occlude pIV

595 channels. Proceedings of the National Academy of Sciences of the United States of America.

$596 \quad 2001 ; 98: 9359-9364$.

597 Marquez, L. M., R. S. Redman, R. J. Rodriguez, and M. J. Roossinck. A virus in a fungus in a

598 plant: three-way symbiosis required for thermal tolerance. Science.2007; 316:201-201.

599 Marvin, D. A., and B. Hohn. Filamentous bacterial viruses. Bacteriol Rev. 1969; 33:172-209.

600 May, R. M., and R. M. Anderson. Epidemiology and Genetics in the Coevolution of Parasites

601 and Hosts. Proceedings of the Royal Society of London Series A: Mathematical Physical and

$602 \quad$ Engineering Sciences. 1983; 390:219-219.

603 Mazaheri Nezhad Fard, R., M.D. Barton, and M.W. Heuzenroeder. Bacteriophage-mediated

604 transduction of antibiotic resistance in enterococci. Letters in Applied Microbiology. 2011;

$605 \quad 52: 559-564$.

606 Merriam, V. Stability of the carrier state in bacteriophage M13-infected cells. Journal of

607 Virology. 1977; 21 (3): 880-888.

608 Model, P., G. Jovanovic, and J. Dworkin. The Escherichia coli phage-shock-protein (psp)

609 operon. Molecular Microbiology. 1997; 24:255-261. 
610 Novak, M., T. Pfeiffer, R.E. Lenski, U. Sauer, and S. Bonhoeffer. Experimental tests for an

611 evolutionary trade-off between growth rate and yield in E. coli. The American Naturalist.

$612 \quad 2006 ; 168(2): 242-251$.

613 Oliver, T. H., S. R. Leather, and J. M. Cook. Tolerance traits and the stability of mutualism.

614 Oikos. 2009; 118:346-352.

615 R Core Team (2015). R: A language and environment for statistical computing. R

616 Foundation for Statistical Computing, Vienna, Austria.

617 Read, A. F. The evolution of virulence. Trends in Microbiology. 1994; 2:73-76.

618 Rice, S. A., C. H. Tan, P. J. Mikkelsen, V. Kung, J. Woo, M. Tay, A. Hauser, D. McDougald, J.

619 S. Webb, and S. Kjelleberg. The biofilm life cycle and virulence of Pseudomonas aeruginosa

620 are dependent on a filamentous prophage. ISME Journal. 2009; 3:271-282.

621 Sachs, J. L., M. O. Ehinger, and E. L. Simms. Origins of cheating and loss of symbiosis in wild 622 Bradyrhizobium. Journal of Evolutionary Biology. 2010; 23:1075-1089.

623 Sachs, J. L., R. G. Skophammer, and J. U. Regus. Evolutionary transitions in bacterial symbiosis.

624 Proceedings of the National Academy of Sciences of the United States of America. 2011;

$625 \quad 108: 10800-10807$.

626 Sambrook, J., E.F. Fritsch, and T. Maniatis. Molecular Cloning Vol 2. New York: Cold Spring 627 Harbor Laboratory Press. 1989.

628 Shapiro, J. W., and P. E. Turner. The impact of transmission mode on the evolution of benefits 629 provided by microbial symbionts. Ecology and Evolution. 2014; 4 (17): 3350-3361.

630 Sokal, R.R. \& F.J. Rohlf (2012). Biometry. Fourth Edition. W.H. Freeman and Company. New 631 York 
632 Summers, M. D., and S. D. Dibhajj. Polydnavirus-Facilitated Endoparasite Protection against

633 Host Immune Defenses. Proceedings of the National Academy of Sciences of the United 634 States of America. 1995; 92:29-36.

635 Turner, P. E., N. M. Morales, B. W. Alto, and S. K. Remold. Role of Evolved Host Breadth in 636 the Initial Emergence of an Rna Virus. Evolution. 2010; 64:3273-3286.

637 Venables, W. N. \& Ripley, B. D. (2002) Modern Applied Statistics with S. Fourth

638 Edition. Springer, New York.

639 Waldor, M. K., and J. J. Mekalanos. Lysogenic conversion by a filamentous phage encoding 640 cholera toxin. Science. 1996; 272:1910-1914.

641 Weeks, A. R., M. Turelli, W. R. Harcombe, K. T. Reynolds, and A. A. Hoffmann. From parasite 642 to mutualist: Rapid evolution of Wolbachia in natural populations of Drosophila. Plos 643 Biology. 2007; 5:997-1005.

644 Wilkinson, D. M., and T. N. Sherratt. Horizontally acquired mutualisms, an unsolved problem in 645 ecology? Oikos. 2001; 92:377-384. 


\section{Figure Captions}

647

648 Figure 1. Diagram of passaging protocols. In each of treatments N, L, M, and U the day $n$ 649 culture is diluted directly by a factor of $1: 10^{2}$ into fresh medium for day $n+1$. Uninfected 650 ancestral E. coli ("naïve" E. coli) is grown in the same day $n$ plate and is added as a supplement

651 of susceptible hosts in treatments $\mathrm{L}$ and $\mathrm{M}$. These naïve bacteria make up $\sim 1 \%$ and $\sim 50 \%$ of the 652 initial bacterial density in day $n+1$ wells for treatments $\mathrm{L}$ and M, respectively. In treatment C, 653 the day $n$ culture is centrifuged, and the supernatant is diluted by 1:10 6 before being combined 654 with naïve bacteria in the day $n+1$ plate.

655

Figure 2: Scatterplot of maximum $\mathrm{OD}_{600}$ against maximum growth rate from all assays. 657

Figure 3: Maximum $\mathrm{OD}_{600}$ (a) and Maximum growth rate (b) of evolved $E$. coli infected with co-resident phage from each treatment. The midline in each bar indicates the mean for that treatment. Individual points are the means of triplicate assays for each population. The

661 dashed line depicts the mean peak density (a) or mean growth rate (b) of uninfected, ancestral 662 bacteria.

663

664 Figure 4: Maximum $\mathbf{O D}_{600}$ (a) and Maximum growth rate (b) of ancestral $E$. coli infected 665 with evolved phage from each experimental treatment. The midline in each bar indicates the 666 mean for that treatment. Individual points are the means of duplicate assays for each population.

667 The dashed line depicts the mean peak density (a) or mean growth rate (b) of uninfected, 668 ancestral bacteria. 
Figure 1 (on next page)

Diagram of experimental setup 


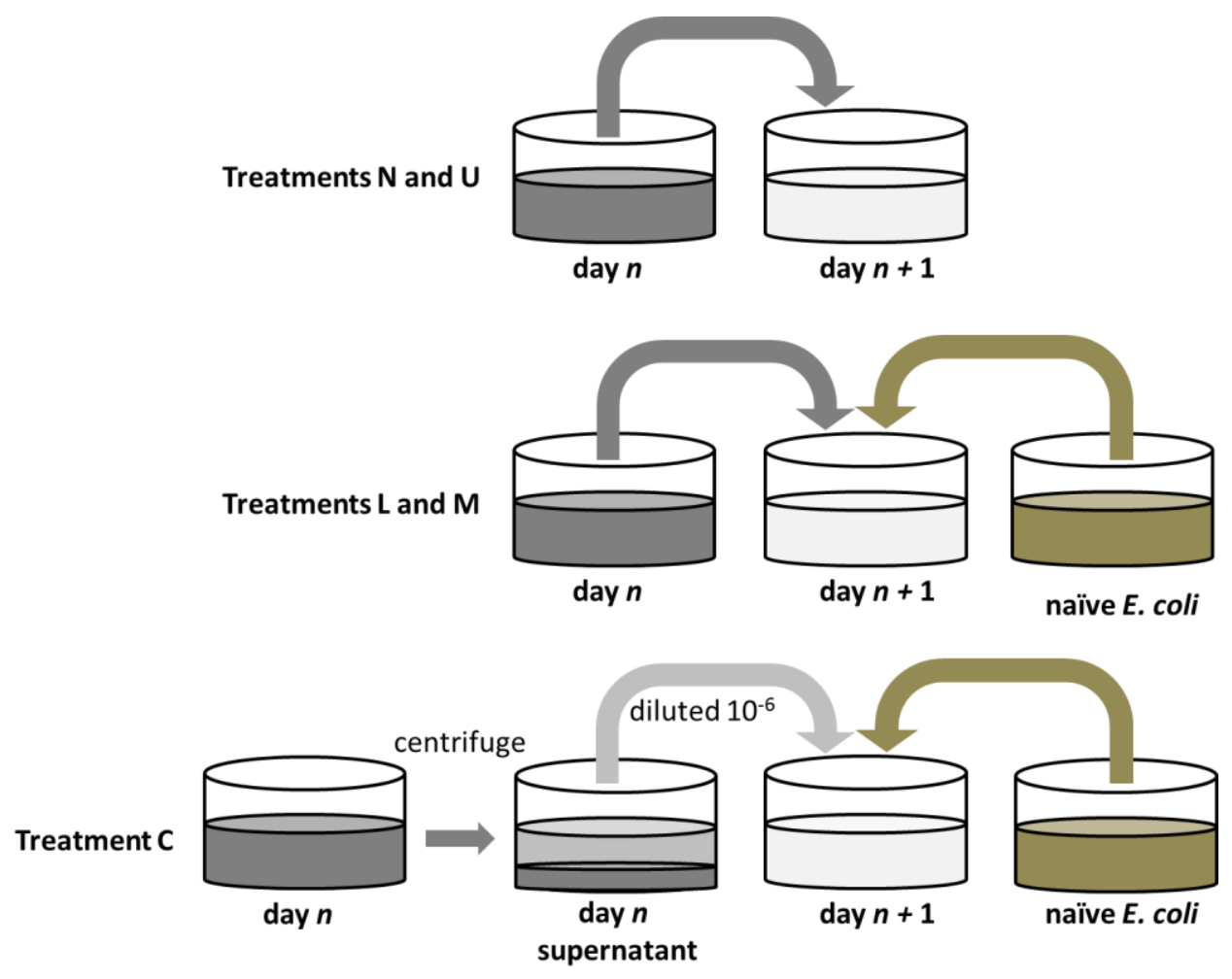


Figure 2 (on next page)

Plot of Rate vs Yield in experiment 


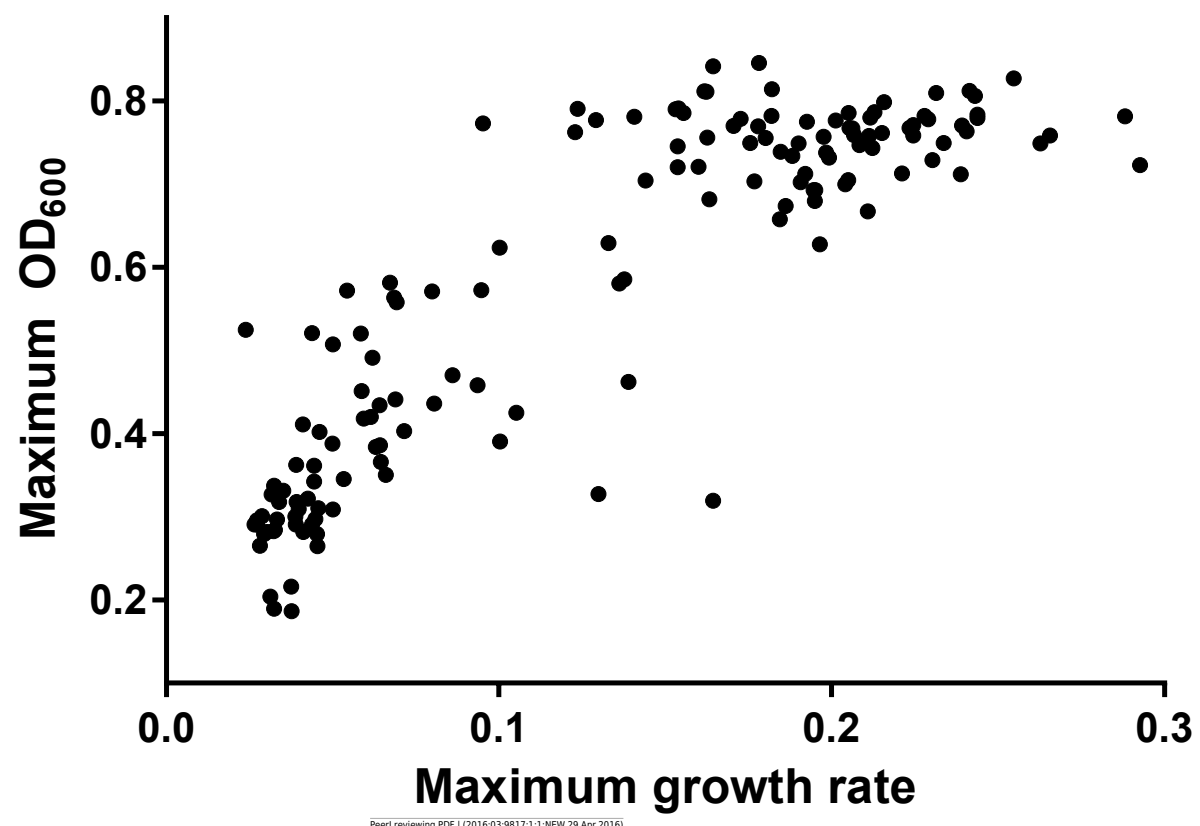


Figure 3 (on next page)

Growth of evolved bacteria across treatments 
(a)

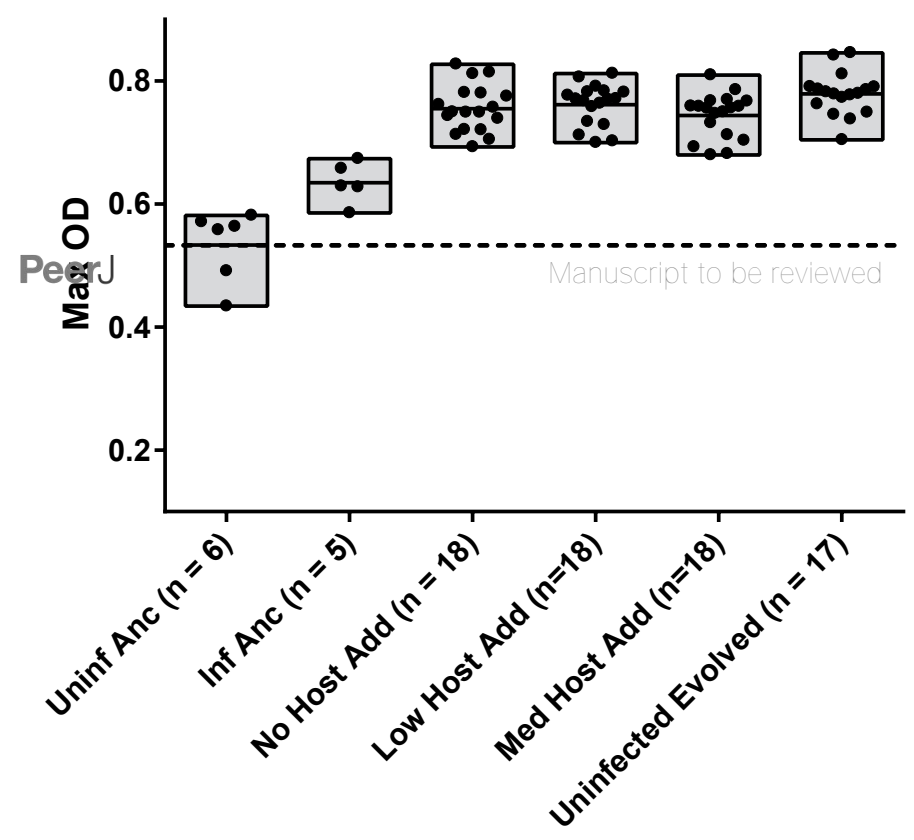

(b)

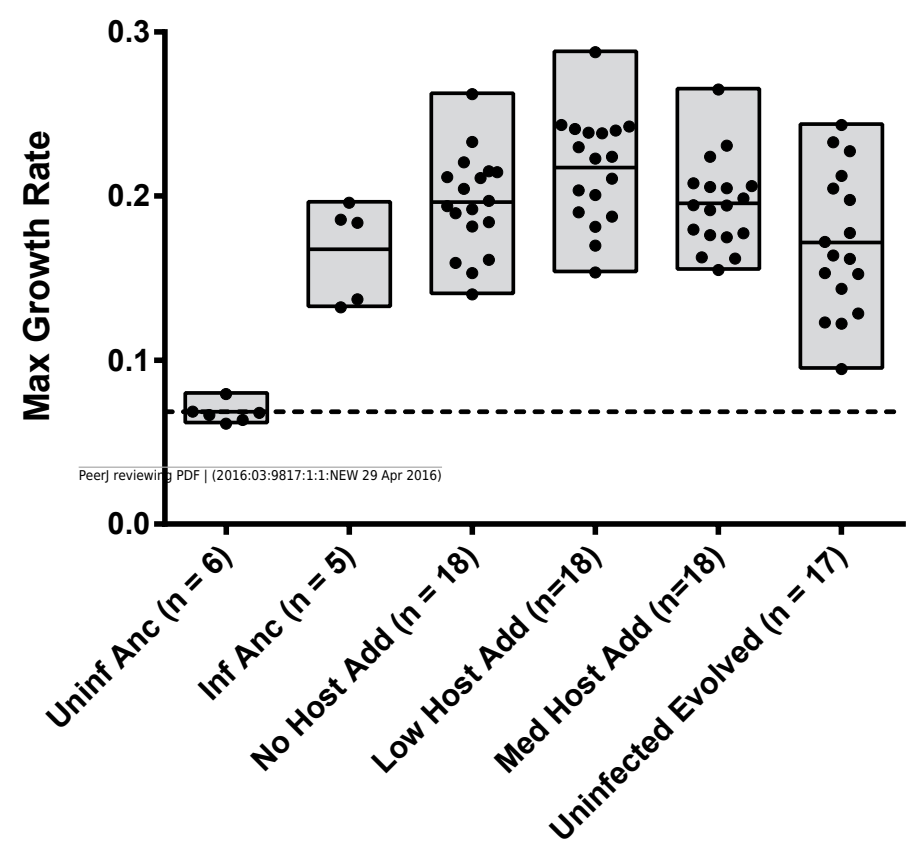


Figure 4 (on next page)

Growth of ancestral bacteria infected with evolved phage 
(a)

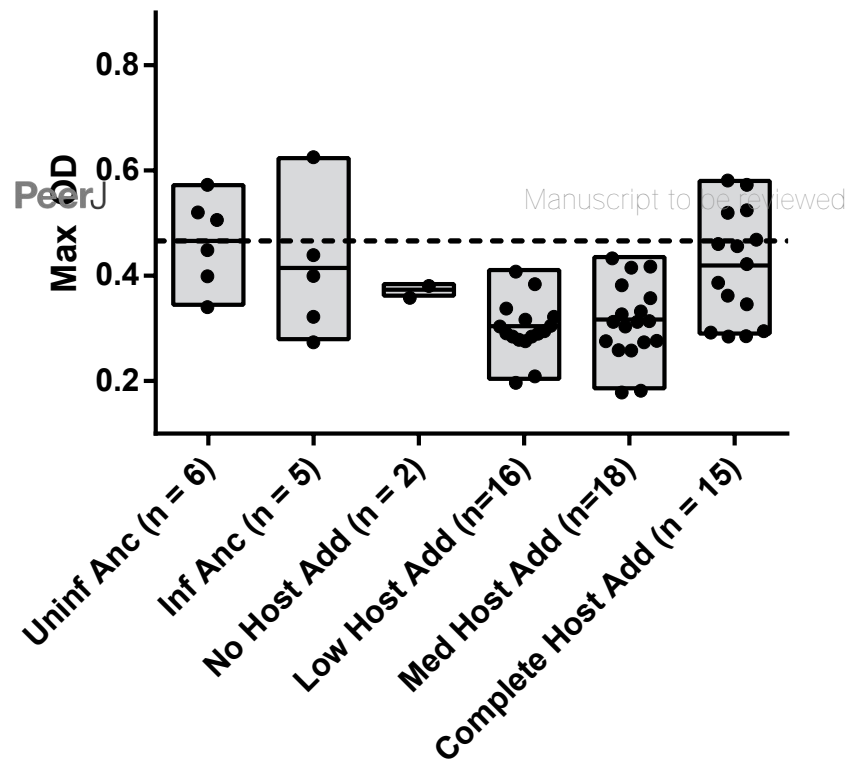

(b)

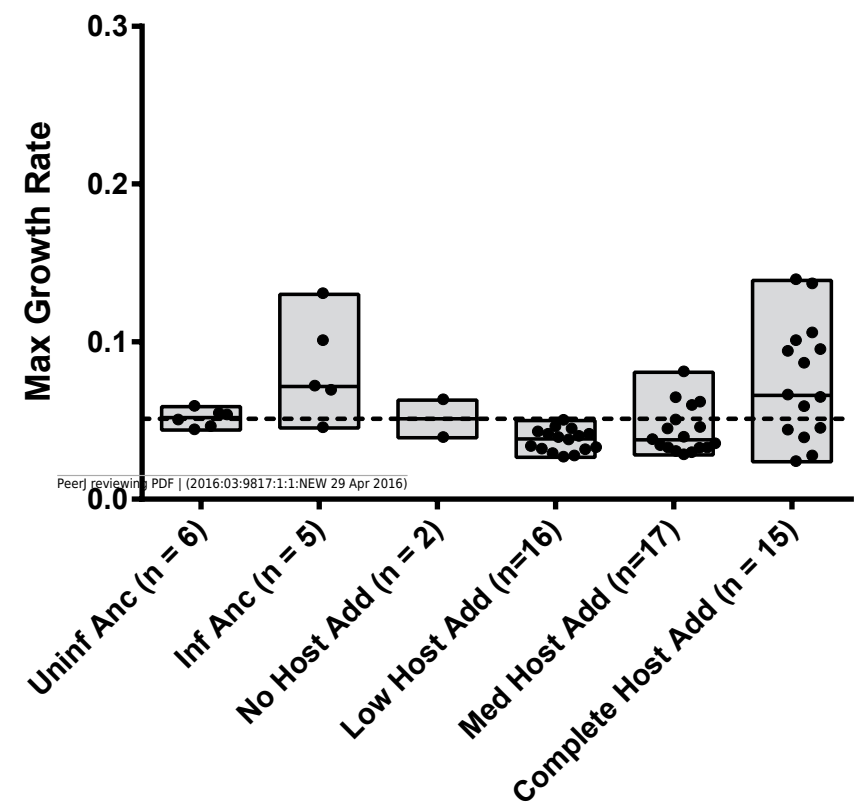




\section{Table 1 (on next page)}

Density data for evolved bacteria across treatments 
1 Table 1a. One-way ANOVA comparing maximum $\mathrm{OD}_{600}$ for evolved, infected bacteria

\begin{tabular}{lccc}
\hline $\begin{array}{l}\text { Treatments } \\
\text { Compared }\end{array}$ & df & F & p-value \\
\hline N,L,M,U,IA & 4 & 16.640 & $1.16 \mathrm{e}-09 * *$ \\
N,L,M,U & 3 & 2.971 & $0.0379 *$ \\
N,L,M,IA & 3 & 17.610 & $3.91 \mathrm{e}-08 * *$ \\
N,L,M & 2 & 1.157 & 0.3220
\end{tabular}

$2 \mathrm{~N}=$ No Host Addition, $\mathrm{L}=$ Low Host Addition, $\mathrm{M}=$ Medium Host Addition, $\mathrm{U}=$ Uninfected Evolved,

$3 \mathrm{UA}=$ Uninfected Ancestor, IA $=$ Infected Ancestor, $* \mathrm{p}<0.05, * * \mathrm{p}<0.01$.

4

5 Table 1b. Comparison of maximum $\mathrm{OD}_{600}$ by treatment for evolved, infected bacteria

\begin{tabular}{|c|c|c|c|}
\hline $\begin{array}{l}\text { Comparison } \\
\text { (A vs B) }\end{array}$ & $\begin{array}{c}\text { Difference } \\
(\mathrm{A}-\mathrm{B})\end{array}$ & $\mathrm{t}$ & p-value \\
\hline NLMU vs IA & 0.1247 & 7.3008 & $2.69 \mathrm{e}-10 * *$ \\
\hline NLM vs U & -0.0254 & 2.5559 & 0.0128 \\
\hline NLM vs IA & 0.1186 & 7.0844 & $2.30 \mathrm{e}-09 * *$ \\
\hline $\mathrm{N}$ vs IA & 0.1201 & 6.3696 & $2.58 \mathrm{e}-06 * *$ \\
\hline L vs IA & 0.1269 & 7.5210 & $2.18 \mathrm{e}-07 * *$ \\
\hline M vs IA & 0.1079 & 6.0449 & $5.34 \mathrm{e}-06 * *$ \\
\hline U vs IA & 0.1440 & 8.1821 & $8.22 \mathrm{e}-08 * *$ \\
\hline U vs UA & 0.2456 & 12.4590 & $3.63 \mathrm{e}-11 * *$ \\
\hline UA vs IA & -0.1016 & 3.4437 & $7.35 \mathrm{e}-03 * *$ \\
\hline
\end{tabular}


Table 2 (on next page)

Growth rate data for evolved bacteria across treatments 
1 Table 2a. One-way ANOVA comparing growth rate for evolved, infected bacteria

\begin{tabular}{lccc}
\hline $\begin{array}{l}\text { Treatments } \\
\text { Compared }\end{array}$ & df & F & p-value \\
\hline N,L,M,U,IA & 4 & 4.784 & $0.0018^{* *}$ \\
N,L,M,U & 3 & 5.204 & $0.0027^{* *}$ \\
N,L,M,IA & 3 & 3.861 & $0.0141^{*}$ \\
N,L,M & 2 & 2.630 & 0.0819
\end{tabular}

$2 \mathrm{~N}=$ No Host Addition, $\mathrm{L}=$ Low Host Addition, $\mathrm{M}=$ Medium Host Addition, $\mathrm{U}=$ Uninfected Evolved,

$3 \mathrm{UA}=$ Uninfected Ancestor, IA $=$ Infected Ancestor, $* \mathrm{p}<0.05, * * \mathrm{p}<0.01$.

4

5 Table $2 \mathrm{~b}$. Comparison of growth rate by treatment for evolved, infected bacteria

\begin{tabular}{llll}
\hline $\begin{array}{l}\text { Comparison } \\
\text { (A vs B })\end{array}$ & $\begin{array}{c}\text { Difference } \\
(\mathrm{A}-\mathrm{B})\end{array}$ & $\mathrm{t}$ & \multicolumn{1}{c}{$\mathrm{p}$-value } \\
\hline NLMU vs IA & 0.1521 & 1.6780 & 0.0976 \\
NLM vs U & 0.1902 & 3.3065 & $0.0015^{* *}$ \\
NLM vs IA & 0.1977 & 2.4393 & 0.0179 \\
N vs IA & 0.1700 & 1.8928 & 0.0723 \\
L vs IA & 0.2634 & 3.0702 & $0.0058^{* *}$ \\
M vs IA & 0.1596 & 2.0027 & 0.0583 \\
U vs IA & 0.0074 & 0.2056 & 0.8392 \\
U vs UA & 0.8918 & 5.7697 & $1.00 \mathrm{e}-05^{* *}$ \\
UA vs IA & -0.8844 & -8.0056 & $2.00 \mathrm{e}-05^{* *}$ \\
\hline
\end{tabular}

$6 \mathrm{~N}=$ No Host Addition, $\mathrm{L}=$ Low Host Addition, $\mathrm{M}=$ Medium Host Addition, $\mathrm{U}=$ Uninfected Evolved,

$7 \mathrm{UA}=$ Uninfected Ancestor, IA $=$ Infected Ancestor, $* *$ significant at $\alpha<0.05$ after Bonferroni correction 8 for multiple comparisons 


\section{Table 3 (on next page)}

Density data for ancestral bacteria infected by evolved phage 
1 Table 3a. One-way ANOVA comparing maximum $\mathbf{O D}_{600}$ for infections of ancestral bacteria

\begin{tabular}{lccl}
\hline $\begin{array}{l}\text { Treatments } \\
\text { Compared }\end{array}$ & df & F & \multicolumn{1}{c}{ p-value } \\
\hline N,L,M,C,IA & 4 & 5.155 & $0.0014^{* *}$ \\
N,L,M,C,UA & 4 & 7.873 & $4.86 \mathrm{e}-05^{* *}$ \\
N,L,M,IA & 3 & 2.705 & 0.0593 \\
N,L,M,UA & 3 & 7.602 & $0.0004^{* *}$ \\
N,L,M,C & 3 & 6.440 & $0.0010^{* *}$ \\
N,L,M & 2 & 1.009 & 0.3756 \\
L,M,IA & 2 & 3.424 & $0.0435^{*}$ \\
L,M,UA & 2 & 10.686 & $0.0002^{* *}$
\end{tabular}

$2 \mathrm{~N}=$ No Host Addition, $\mathrm{L}=$ Low Host Addition, $\mathrm{M}=$ Medium Host Addition, $\mathrm{C}=$ Complete Host

3 Addition, $\mathrm{UA}=$ Uninfected Ancestor, $\mathrm{IA}=$ Infected Ancestor, ${ }^{*} \mathrm{p}<0.05$, ${ }^{*} \mathrm{p}<0.01$ 4 .

5 Table 3b. Comparison of maximum $\mathrm{OD}_{600}$ by treatment for infections of ancestral bacteria

\begin{tabular}{llll}
\hline $\begin{array}{l}\text { Comparison } \\
(\text { A vs B })\end{array}$ & $\begin{array}{c}\text { Difference } \\
(\mathrm{A}-\mathrm{B})\end{array}$ & $\mathrm{t}$ & \multicolumn{1}{c}{ p-value } \\
\hline NLMC vs IA & -0.1115 & -1.2295 & 0.1453 \\
NLMC vs UA & -0.1209 & -3.7191 & $0.0041^{* *}$ \\
NLM vs C & -0.1055 & -3.8222 & $0.0001^{* *}$ \\
NLM vs IA & -0.1425 & -2.5314 & 0.0155 \\
NLM vs UA & -0.1520 & -4.7197 & $4.84 \mathrm{e}-05^{* *}$ \\
C vs IA & -0.0370 & -0.1361 & 0.8809 \\
C vs UA & -0.0465 & -1.1810 & 0.3095 \\
UA vs IA & -0.0095 & -0.8824 & 0.3795
\end{tabular}

$6 \mathrm{~N}=$ No Host Addition, $\mathrm{L}=$ Low Host Addition, $\mathrm{M}=$ Medium Host Addition, $\mathrm{C}=$ Complete Host

7 Addition, $\mathrm{UA}=$ Uninfected Ancestor, $\mathrm{IA}=$ Infected Ancestor, ** significant at $\alpha<0.05$ after Bonferroni

8 correction for multiple comparisons 


\section{Table 4(on next page)}

Growth rate data of ancestral bacteria infected by evolved phage 
1 Table 4a. One-way ANOVA comparing growth rate for infections of ancestral bacteria

\begin{tabular}{lccl}
\hline $\begin{array}{l}\text { Treatments } \\
\text { Compared }\end{array}$ & df & F & \multicolumn{1}{c}{ p-value } \\
\hline N,L,M,C,IA & 4 & 6.047 & $0.0233^{*}$ \\
N,L,M,C,UA & 4 & 5.946 & $0.0211^{*}$ \\
N,L,M,IA & 3 & 5.881 & $0.0023^{* *}$ \\
N,L,M,UA & 3 & 2.463 & 0.0773 \\
N,L,M,C & 3 & 3.851 & 0.0924 \\
N,L,M & 2 & 1.697 & 0.1988 \\
L,M,C & 2 & 6.879 & $0.0024^{* *}$
\end{tabular}

$2 \mathrm{~N}=$ No Host Addition, $\mathrm{L}=$ Low Host Addition, $\mathrm{M}=$ Medium Host Addition, $\mathrm{C}=$ Complete Host

3 Addition, $\mathrm{UA}=$ Uninfected Ancestor, $\mathrm{IA}=$ Infected Ancestor, ${ }^{*} \mathrm{p}<0.05,{ }^{* *} \mathrm{p}<0.01$

4

5 Table $4 \mathrm{~b}$. Comparison of growth rate by treatment for infections of ancestral bacteria

\begin{tabular}{llll}
\hline $\begin{array}{l}\text { Comparison } \\
\text { (A vs B) }\end{array}$ & $\begin{array}{c}\text { Difference } \\
(\mathrm{A}-\mathrm{B})\end{array}$ & $\mathrm{t}$ & $\mathrm{p}$-value \\
\hline NLMC vs IA & -0.6719 & -3.2080 & 0.0219 \\
NLMC vs UA & -0.0763 & -0.7808 & 0.4382 \\
NLM vs C & -0.4741 & -2.8834 & $0.0014^{* *}$ \\
LM vs IA & -0.8114 & -4.1434 & $0.0006^{* *}$ \\
LM vs UA & -0.2158 & -3.7602 & 0.0618 \\
C vs IA & -0.3373 & -0.0006 & 0.4619 \\
C vs UA & 0.2583 & 0.0618 & 0.4870 \\
UA vs IA & -0.5956 & -2.358 & 0.0311 \\
\hline
\end{tabular}

$6 \mathrm{~N}=$ No Host Addition, $\mathrm{L}=$ Low Host Addition, $\mathrm{M}=$ Medium Host Addition, $\mathrm{C}=$ Complete Host

7 Addition, $\mathrm{UA}=$ Uninfected Ancestor, $\mathrm{IA}=$ Infected Ancestor, $* *$ significant at $\alpha<0.05$ after Bonferroni

8 correction for multiple comparisons. 